\title{
Artificial Neural Network (ANN) Approach for Predicting Friction Coefficient of Roller Burnishing AL6061
}

\author{
S. H. Tang, N. Hakim, W. Khaksar, S. Sulaiman, M. K. A. Ariffin, and R. Samin
}

\begin{abstract}
Artificial Neural Network (ANN) approach is a fascinating mathematical tool, which can be used to simulate a wide variety of complex scientific and engineering problems. Due to its highly reliable prediction quality, the usage of it is growing rigorously and had already become an ultimate tool for various applications in the field of engineering. In this study an ANN technique was used to predict friction coefficient of roller burnishing AL6061 for two orientations which is parallel burnishing orientation (PB) and cross burnishing orientation (CB). The input parameters were defined by widths of roller curvature $(7.5 \mathrm{~mm}, 8 \mathrm{~mm}$ and $8.5 \mathrm{~mm})$, burnishing speeds (110rpm, 230rpm, 330rpm and 490rpm), and burnishing forces $(155.06 \mathrm{~N}, 197.45 \mathrm{~N}, 239.83 \mathrm{~N}$ and $282.22 \mathrm{~N})$ while the output parameter was friction coefficient. 173 data was used for training the ANN and another 115 data was used to test the ANN. 60 different configurations of ANN was trained by using 6 different training algorithms. It was found that feed-forward back-propagation network with 15 neurons in hidden layer that was trained by Levenberg-Marquardt training algorithm gave the best result when compared to other training algorithms used. From the results it was found that the training performance and prediction performance was 0.000809 and 0.710 respectively. From this study, it became obvious that the selected ANN with the configuration and training algorithm proved to be the most suitable among the other ANN investigated for similar applications.
\end{abstract}

Index Terms-Friction coefficient; neural network; roller burnishing AL6061.

\section{INTRODUCTION}

Heuristic Techniques like artificial intelligence, Monte Carlo simulation and other applied problem solving approaches have been used in various areas with proven efficiencies [1]. Recently, Artificial Neural Network (ANN) approach has been widely applied to various relevant engineering fields. ANN is not a new technique and has been studied since the 1940s and was almost forgotten during the 1970 s, but reappeared in 1980 s as a possible alternative to traditional computing [2]. Many researchers have been conducted using ANN due to reliable of this method compare to another method. ANN is modeled after the structure of the brain, and therefore even the terminology is borrowed from neuroscience. Inspired by biological neurons, ANN is

Manuscript received on August 11, revised November 11. 2012. This work was supported by Universiti Putra Malaysia.

S. H. Tang, W. Khaksar, S. Sulaiman, M. K. A. Ariffin, and R. Samin are with the Department of Mechanical and Manufacturing Engineering, Faculty of Engineering, Universiti Putra Malaysia, Selangor, Malaysia (email:saihong@eng.upm.edu.my,email:wkhie@yahoo.com,email:suddin@ eng.upm.edu.my, email:khairol@eng.upm.edu.my )

N. Hakim is with a Malaysian government ministry (e-mail: hakim717@yahoo.com). massively parallel-distributed processor made up of simple processing units (neurons) that connected to each other, which has a natural propensity for storing experiential knowledge and making it available for use. Humans by nature have the ability to learn from the examples. ANN is sharing same ability by resembles the brain function and acquired the knowledge through learning process (training process). ANN can be trained to perform particular function by adjusting the values of weights between the neurons. This is the key to the ability of ANN to achieve learning and memory [3]. Unlike conventional computers that solves problem using the given instructions and algorithms, ANN operates like a "black-box" model, requiring no detailed information about the system or process. Instead, they learn the relationship between the input and output parameters by studying the experimental data.

In today's cost-efficient manufacturing, selection of the process that can help to reduce the additional operations and cost savings is very essential. Thus, roller burnishing process becomes an alternative to conventional finishing process which depends on chip removal. To make it cost-efficient, the process needs to satisfy with low waste and low energy consumption while long cycles of fine machining have to be avoided [4]. Roller burnishing is a chipless post-machining process which is used to eliminate scratches, tool marks, pits and porosity [5].

Lately, researchers have paid more attention on the parameters in roller burnishing process. The effect of roller burnishing parameters such as burnishing force, speed, feed, and roller width contact is studied by mean of experimental [6]. These experiments computed the hardness, roughness, friction and wear of the specimen. ANN can be used to eliminate this time consuming experiment to be time and cost effective.

\section{Developing of the Artificial Neural Network}

This part will demonstrate the use of Neural Network Toolbox in MATLAB to create an Artificial Neural Network (ANN). To make a successful ANN that can be used to predict the friction coefficient, a few steps need to be followed as below:

a) Database collection: the friction coefficient data for Roller Burnishing AL6061 experiment El-Tayeb et al. [6].

b) Generate the input and output for the data.

c) Transfer the data from Excel files to MATLAB files.

d) Develop (choose the architecture of ANN, training functions, training algorithms and parameters of the ANN) the ANN.

e) Train the ANN with the processed data. 
f) Test the trained ANN to evaluated the network performance

g) Use the trained ANN for simulation and prediction.

\section{A. Preparation of Data}

The dataset was taken from available experimental data of friction coefficient for roller burnishing AL6061 [6]. The tribo tests were conducted on dry burnishing surface produced by different widths of roller curvature $(7.5 \mathrm{~mm}$, $8 \mathrm{~mm}$ and $8.5 \mathrm{~mm})$, burnishing speeds (110rpm, 230rpm, $330 \mathrm{rpm}$ and 490rpm), and burnishing forces $(155.06 \mathrm{~N}$, $197.45 \mathrm{~N}, 239.83 \mathrm{~N}$ and $282.22 \mathrm{~N})$. The tribo tests were repeated for two burnishing orientations, i.e. parallel (PB) and crossed (CB). Friction coefficient was recorded for every 10 seconds at different tribo test conditions.

The experimental data taken from El-Tayeb et al. [6] work were classified into inputs and outputs. Four parameters (roller curvature, burnishing speed, burnishing force and time) have been determined from the experimental data to be the inputs. On the other hand, friction coefficient will be the only output. In total, 576 data of friction coefficient were available for different conditions test.

A 288 data from the parallel test and 288 data from the crossed test were selected. Table I shows the sample of experiment data for parallel burnishing orientation (PB).

TABLE I: A SAMPLE OF EXPERIMENT DATA

\begin{tabular}{|c|c|c|c|c|}
\hline $\begin{array}{c}\text { Roller } \\
\text { Curvature } \\
(\mathrm{mm})\end{array}$ & $\begin{array}{c}\text { Burnishing } \\
\text { Speed, } \\
\text { N (rpm) }\end{array}$ & $\begin{array}{l}\text { Burnishing } \\
\text { Force, }(\mathrm{N})\end{array}$ & $\begin{array}{l}\text { Time } \\
\text { Duration } \\
(\mathrm{S})\end{array}$ & $\begin{array}{c}\text { Experimental Friction } \\
\text { Coefficient }(\mu)\end{array}$ \\
\hline 8.5 & 110 & 239.83 & 10 & 0.2815 \\
\hline 8.5 & 110 & 239.83 & 20 & 0.3150 \\
\hline 8.5 & 110 & 239.83 & 30 & 0.3484 \\
\hline 8.5 & 110 & 239.83 & 40 & 0.3150 \\
\hline 8.5 & 110 & 239.83 & 50 & 0.3150 \\
\hline 8.5 & 110 & 239.83 & 60 & 0.2815 \\
\hline 8.5 & 110 & 239.83 & 70 & 0.3150 \\
\hline 8.5 & 110 & 239.83 & 80 & 0.3484 \\
\hline 8.5 & 110 & 239.83 & 90 & 0.3484 \\
\hline 8.5 & 110 & 239.83 & 100 & 0.3150 \\
\hline 8.5 & 110 & 239.83 & 110 & 0.2815 \\
\hline 8.5 & 110 & 239.83 & 120 & 0.3484 \\
\hline 8.5 & 110 & 239.83 & 130 & 0.3150 \\
\hline 8.5 & 110 & 239.83 & 140 & 0.3150 \\
\hline 8.5 & 110 & 239.83 & 150 & 0.2815 \\
\hline 8.5 & 110 & 239.83 & 160 & 0.3150 \\
\hline 8.5 & 110 & 239.83 & 170 & 0.3819 \\
\hline 8.5 & 110 & 239.83 & 180 & 0.3819 \\
\hline
\end{tabular}

\section{B. Designing the ANN}

Multi-layer feed-forward back-propagation networks with different architecture were designed using the MATLAB Toolbox: Neural Network Toolbox. The networks consisted of three layers: input layer; hidden layer; and output layer. There were four input parameters into the network: roller curvature, burnishing speed, burnishing force and time, and one output parameter corresponding to the friction coefficient. Different networks with single and double hidden layers topologies were used, Fig. 1.
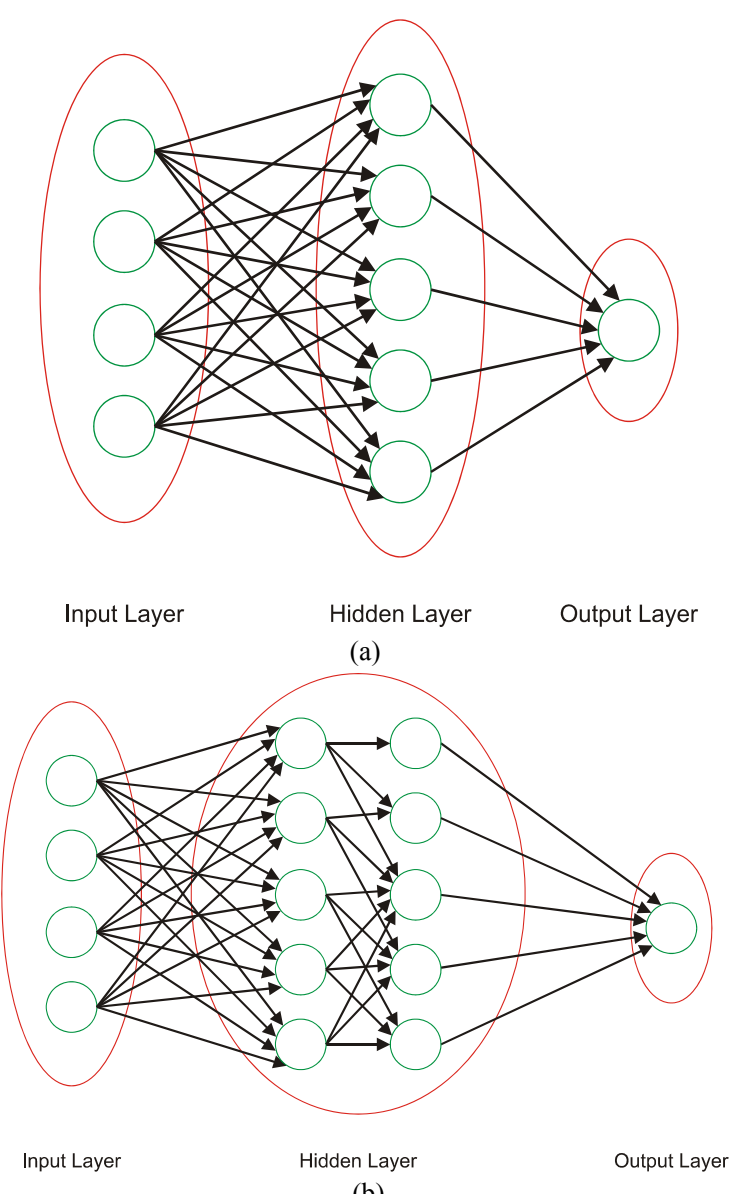

(b)

Fig. 1. Networks with single and double hidden layers, (a) ANN-Single hidden layer, (b) ANN-Double hidden layer

In order to achieve the best results, different training algorithms have been attempted similar to the work done by Zhang et al. [7]. Six different back-propagation training algorithms were used in designing such as BFGS Quasi-Newton (trainbfg), Bayesian Regularization (trainbr), Powell-Beale Conjugate Gradient (traincgb), Adapative Learning Rate (traingdx), Levenberg-Marquardt (trainlm) and Scaled Conjugate Gradient (trainscg). For every training algorithm, ten different configuration has been used, there were 4-[5] $]_{1}-1,4-[10]_{1}-1,4-[15]_{1}-1,4-[5-5]_{2}-1,4-[5-10]_{2}-1$, $4-[5-15]_{2}-1,4-[10-15]_{2}-1,4-[15-20]_{2}-1,4-[20-30]_{2}-1$, and $4-[20-40]_{2}-1$.

For all networks, tan-sigmoid transfer function (tansig) was used in the hidden layers while linear transfer function (purelin) was used in the output layers. The linear transfer function (purelin) was used in the output layer so that the value for the output is not limited between 0 and +1 as in hidden layer by using tan-sigmoid transfer function (tansig).

\section{Training the ANN}

The network was trained by supplying training dataset and letting it change its weights and bias according to some learning algorithm. The performance of the training network now can be determined by its Mean Square Error (MSE). At this point, it should be realized that the training performance of network based on the smallest value of MSE, while the prediction is determined by coefficient of determination $(\mathrm{B} \geq$ $0.9)$. B is defined by how close the prediction value of ANN (output) compare to the target data. The best configuration of 
ANN for each training algorithm can be determined as shown in Table II.

TABLE II: RANKING OF THE BEST NETWORK ARCHITECTURE EVALUATED

\begin{tabular}{|c|c|c|c|c|}
\hline \multicolumn{5}{|c|}{ BY MSE } \\
\hline Rank & $\begin{array}{l}\text { Training } \\
\text { algorithm }\end{array}$ & $\begin{array}{l}\text { Name of the } \\
\text { network }\end{array}$ & $\begin{array}{l}\text { Network's } \\
\text { configuration }\end{array}$ & $\begin{array}{l}\text { Performance } \\
\text { (MSE) }\end{array}$ \\
\hline \multirow[t]{3}{*}{1} & Powell-Beale & & & \\
\hline & Conjugate & networkcgb10 & $4-[20-40]_{2}-1$ & 0.000801 \\
\hline & Gradient & & & \\
\hline \multirow[t]{2}{*}{2} & Adapative & & & \\
\hline & Learning Rate & networkgdx10 & $4-[20-40]_{2}-1$ & 0.000805 \\
\hline \multirow[t]{2}{*}{3} & Levenberg & & & \\
\hline & Marquardt & networklm3 & $4-[15]_{1}-1$ & 0.000809 \\
\hline \multirow[t]{3}{*}{4} & Scaled & & & \\
\hline & Conjugate & networkscg9 & $4-[20-30]_{2}-1$ & 0.000830 \\
\hline & Gradient & & & \\
\hline \multirow[t]{2}{*}{5} & BFGS & & & 0000 \\
\hline & Quasi-Newton & networkbtg7 & $4-[10-15]_{2}-1$ & 0.000924 \\
\hline \multirow[t]{2}{*}{6} & Bayesian & networkbr9 & 4 & 0162000 \\
\hline & Regularization & networkory & 4 & 0.102000 \\
\hline
\end{tabular}

From the Table II, the best network architecture was given by "networkcgb10" with the configuration of $4-[20-40]_{2}-1$ and using Powell-Beale Conjugate Gradient training algorithm. As a reminder, training performance is not actual quality performance of the ANN, therefore, all the networks in the Table 2 need to be evaluated for their prediction quality by testing with test data set.

\section{Test and Evaluate the ANN}

By finishing the training process with satisfactory performance, the testing process will take place. Testing process of ANN requires testing data set to be introduced to the selected ANN in Neural Network Toolbox. Data with four inputs (roller curvature, burnishing speed, burnishing force and time) has been made by "Variable Editor" of MATLAB. This is new data never used before in the ANN during training process.

After we finish the testing process and had predicted value from the ANN, then we can evaluate the performance of the selected ANN. Performance of ANN model cannot be judge from their training performance which was the value of Mean Square Error (MSE). To evaluate the performance of the ANN model, coefficient of determination $(B)$ has been introduced. $B$ is defined by:

$$
B=\frac{\sum_{i=1}^{M} O\left(p^{(i)}\right)-\left(O^{(i)}\right)^{2}}{\sum_{i=1}^{M}\left(O^{(i)}-O\right)^{2}}
$$

where, $O(p(i))$ is the ith predicted value; $O$ is the mean of measure value and $O(i)$ :the ith measured value and $\mathrm{M}$ is number of data.

In simple words, $O(p(i))$ is the ANN predicted value, $O(i)$ is the experimental value, and $O$ is the average value of experimental data.

The coefficient $B$ describes the fit of the ANN's output variable approximation curve to the actual test data output variable curve. Higher $B$ coefficients indicate an ANN with better output approximation capabilities. It is clear that the higher value percentage of $B>=0.9$, the better is the quality [3].

Work has been done to calculate the $B$ for every tested
ANN model in previous section, Table II. Microsoft Excel has been used to calculate the B using the formula in Fig. 2. The value of B for selected ANN from Table II shown as in Table III.

TABLE III: RANKING OF THE BEST NETWORK ARCHITECTURE EVALUATED

\begin{tabular}{cccc}
\multicolumn{3}{c}{ BY B } \\
\hline \hline Rank & $\begin{array}{c}\text { Name of the } \\
\text { Network }\end{array}$ & $\begin{array}{c}\text { Network's } \\
\text { Configuration }\end{array}$ & $\begin{array}{c}\text { Coefficient of } \\
\text { Determination, B }\end{array}$ \\
\hline 1 & networklm3 & $4-[15]_{1}-1$ & 0.710 \\
2 & networkbr9 & $4-[20-30]_{2}-1$ & 0.672 \\
3 & networkbfg7 & $4-[10-15]_{2}-1$ & 0.667 \\
4 & networkscg9 & $4-[20-30]_{2}-1$ & 0.664 \\
5 & networkgdx10 & $4-[20-40]_{2}-1$ & 0.647 \\
6 & networkcgb10 & $4-[20-40]_{2}-1$ & 0.659 \\
\hline \hline
\end{tabular}

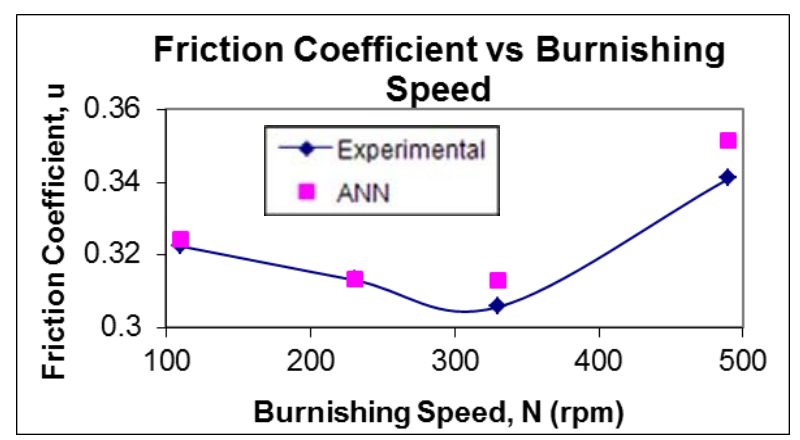

(a)

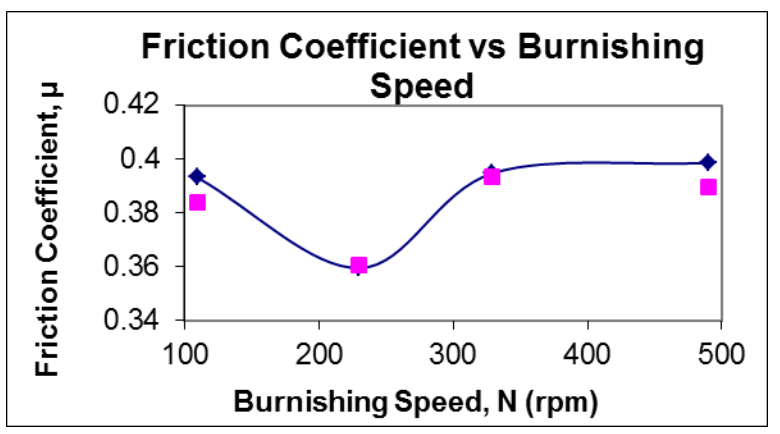

(b)

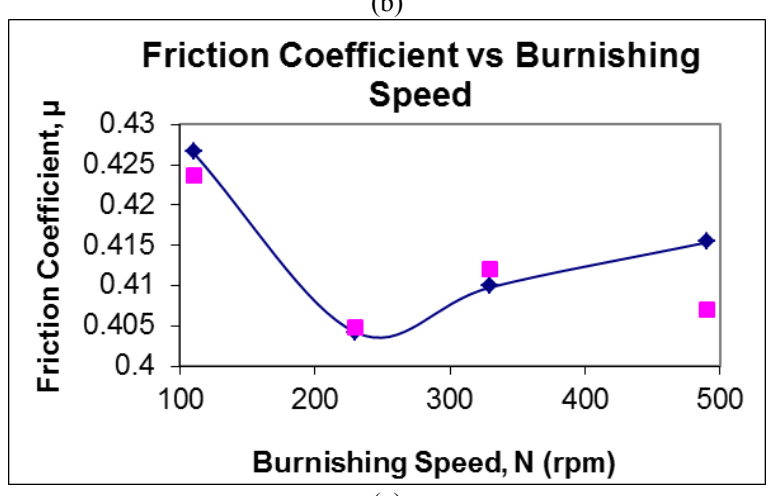

(c)

Fig. 2. Experimental and ANN friction coefficient values at various speeds with $239.83 \mathrm{~N}$ load in PB. (a) $8.5 \mathrm{~mm}$ width of roller curvature, (b) $8 \mathrm{~mm}$ width of roller curvature, (c) $8 \mathrm{~mm}$ width of roller curvature.

Table III shows that the ANN model "networklm3" with 4-[15] $]_{1}-1$ configuration and Levenberg-Marquardt training algorithm gave the best prediction quality with $\mathrm{B}=0.71$, following by "networkbr9", "networkbfg7", "networkscg9", "networkgdx10" and "networkcgb10". In previous table (Table II), "networkcgb10" dominant the first place due to its 
high training performance (lowest MSE) but when it tested with test data set, it is in last place due to lowest coefficient of determination (B).

It is clear to see that the training performance is not an actual quality of the ANN. Therefore, "networklm3" will be used for prediction of friction coefficient for roller burnishing AL6061.

\section{PREDICTION AND Discussion}

After the network are trained, tested, and evaluated successfully, the best network has been selected to make a prediction. So, the developed ANN ("networklm3") model was used to predict the friction coefficient and its results then can be compared to the experimental results.

ANN predicted friction coefficient values at various speeds are shown in Fig. 3 and 4. The predicted values for parallel burnishing orientation $(\mathrm{PB})$ are almost same with the experimental values. There are always two values that occurred at the same point as shown in Figure 2(a) and 2(b), while the other values are almost near to each other. On the other hand, ANN shows lack of consistency in crossed burnishing orientation $(\mathrm{CB})$ as shown in Figure 3 . This could be due to the non-linear experimental data that lead to this problem.

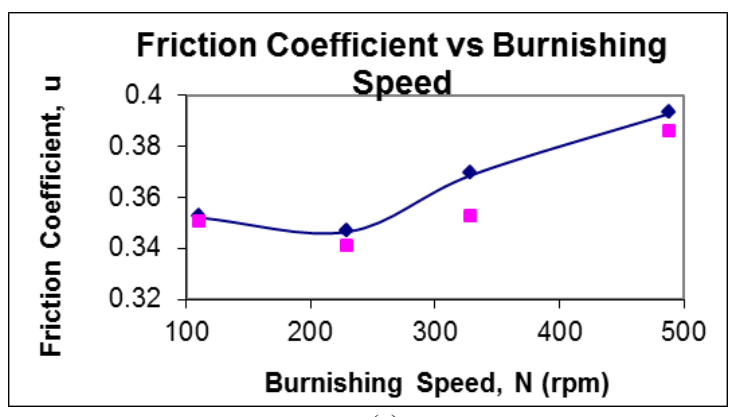

(a)

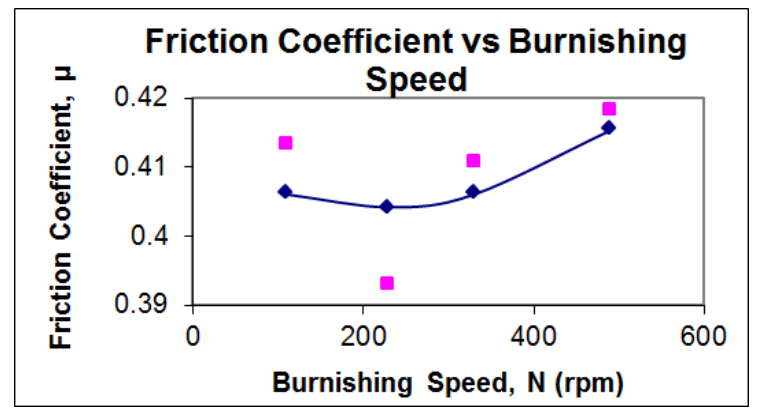

(b)

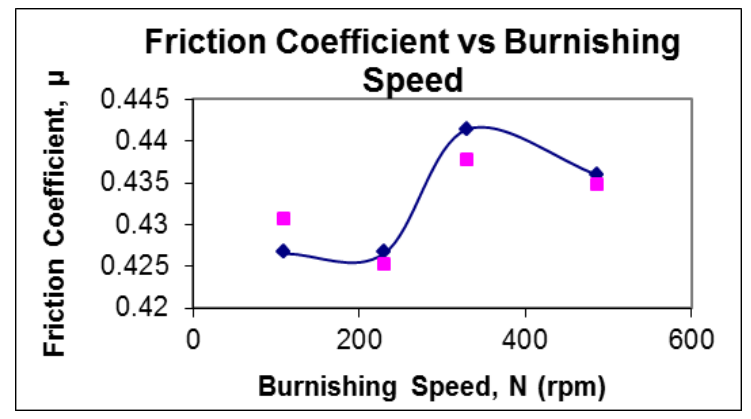

(c)

Fig. 3. Experimental and ANN friction coefficient values at various speeds with $239.83 \mathrm{~N}$ load in $\mathrm{CB}$, (a) $8.5 \mathrm{~mm}$ width of roller curvature, (b) $8 \mathrm{~mm}$ width of roller curvature, (c) $7.5 \mathrm{~mm}$ width of roller curvature.
Fig. 4 shows that ANN predicted values at various forces with different burnishing orientations. The experimental and ANN predicted values are at the same trend for every points shown in Fig. 4(a) and 4(b), therefore the ability of ANN to predict the friction coefficient at various force is very good.

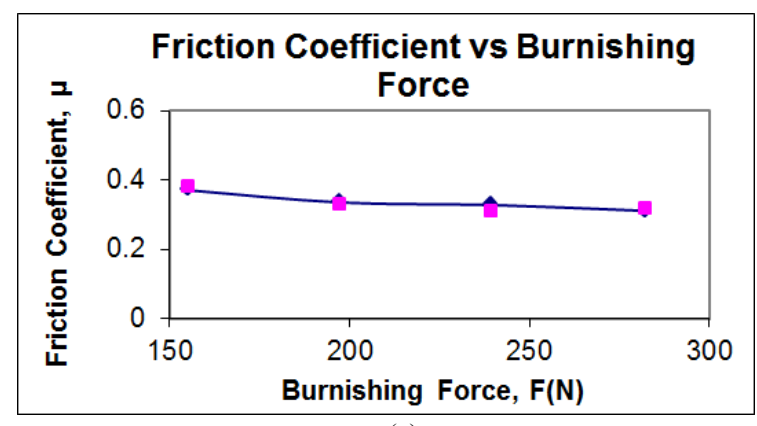

(a)

Fig. 4 (a) . Experimental and ANN friction coefficient values at various forces for 330rpm speed and $8.5 \mathrm{~mm}$ width of roller curvature in different orientation - Parallel burnishing orientation (PB).

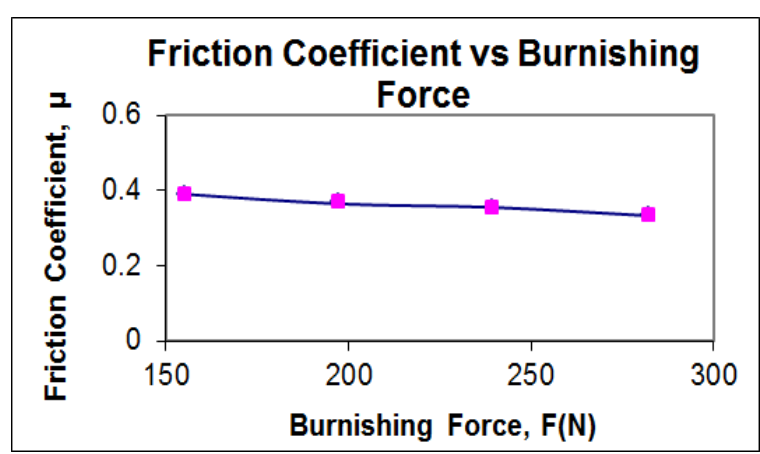

(b)

Fig. 4 (b). Experimental and ANN friction coefficient values at various forces for $330 \mathrm{rpm}$ speed and $8.5 \mathrm{~mm}$ width of roller curvature in different orientation - Crossed burnishing orientation (CB).

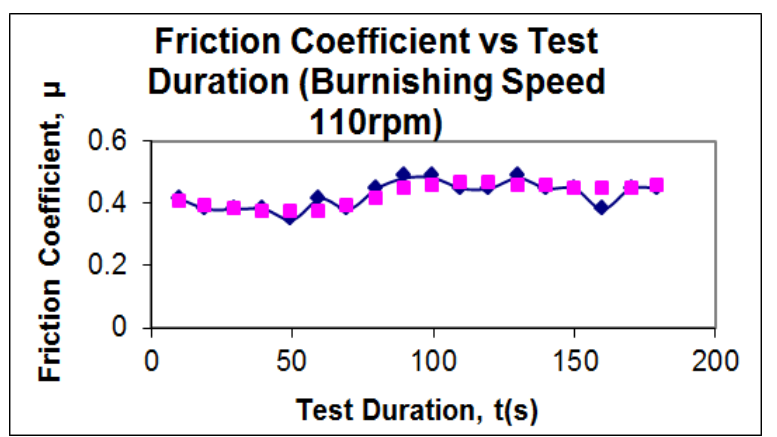

(a)

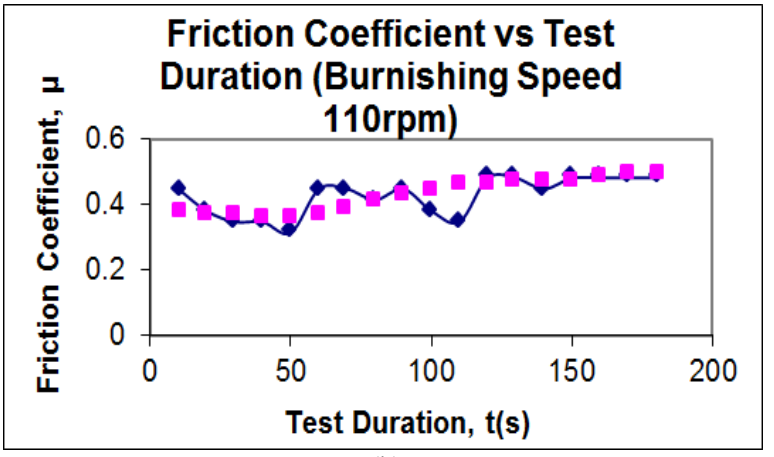

(b)

Fig. 5. Experimental and ANN friction coefficient values at $7.5 \mathrm{~mm}$ width of roller curvature, $110 \mathrm{rpm}$ and $239.83 \mathrm{~N}$ load in different orientation, (a) Parallel burnishing orientation (PB), (b) Crossed burnishing orientation (PB). 
Then, predicted friction coefficient values on various parameters (width roller curvature, burnishing speed, and burnishing orientation) with respect to time are shows in Fig. 5,6 , and 7 . The results indicated that the ANN's ability in predicting the friction coefficient is excellent in parallel burnishing orientation (PB) than crossed burnishing orientation (CB).

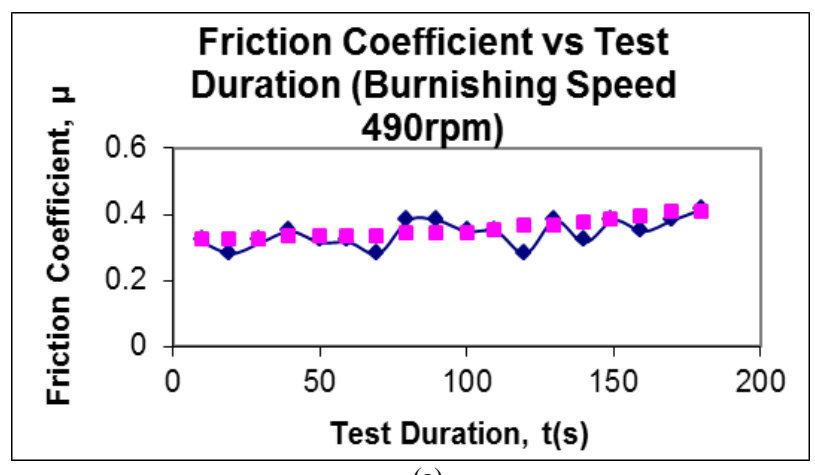

(a)

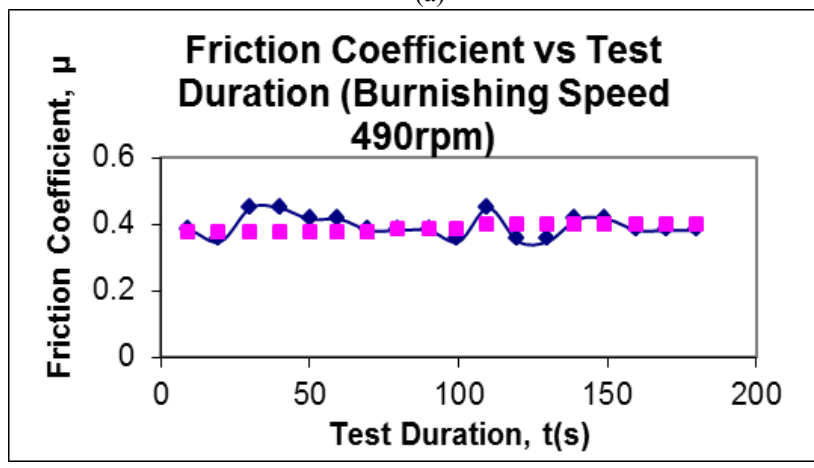

(b)

Fig. 6. Experimental and ANN friction coefficient values at $8.5 \mathrm{~mm}$ width of roller curvature, $490 \mathrm{rpm}$ and $239.83 \mathrm{~N}$ load in different orientation, (a)

Parallel burnishing orientation (PB), (b) Crossed burnishing orientation (CB).

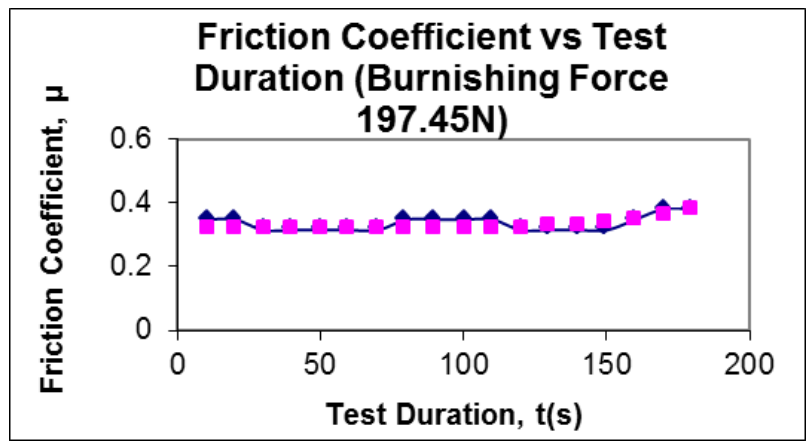

(a)

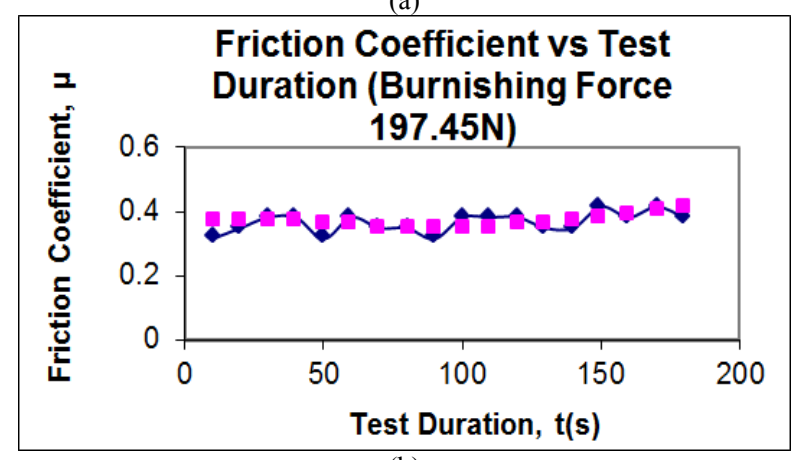

(b)

Fig. 7. Experimental and ANN friction coefficient values at $8.5 \mathrm{~mm}$ width of roller curvature, 330rpm and $197.45 \mathrm{~N}$ load in different orientation, (a) Parallel burnishing orientation (PB), (b) Crossed burnishing orientation (CB).

\section{CONCLUSION}

A Feed-forward Neural Network with Back-propagation training algorithm is proposed to predict the friction coefficient in this project. In the first phase, the experimental data for parallel burnishing orientation (PB) and crossed burnishing orientation (CB) is used to train the ANN with various architectures. In order to find the best architecture of ANN, the ANN that has lowest MSE (Mean Square Error) during training process is tested using test data set and its prediction performance is indicated by coefficient of determination (B).

Single layer ANN with 15 neurons in hidden layer and using Levenberg-Marquardt training algorithm showed the highest $\mathrm{B}$ which is 0.71 .

It is proved that one layer ANN can approximate complex non-liner function. Finally, based on the relatively large number of training data (173), the well-trained ANN has been used to predict the friction factor at various parameters and showed promising result especially in parallel burnishing orientation (PB). The results obtained are close to experimental data; therefore by using trained ANN, the intermediate results that were not obtained in the experiment can be predicted.

It is proven that the determination of the ANN's architecture (input parameters, activation function, number of neurons in hidden layer, number of hidden layer, size of training data set and training algorithm) has directly affected the performance of prediction quality. Careful step should be improvised to determine the best architecture for given problem.

\section{REFERENCES}

[1] S. M. Homayouni, S. H. Tang, and N. Ismail, "Development of genetic fuzzy logic controller for complex production systems," Computers \& Industrial Engineering, vol. 57, no. 4, 2009, pp. 1247-1257.

[2] M. R. Veronez, A. B. Thum, A. S. Luz, and D. R. D. Silva, "Artificial neural networks applied in the determination of soil surface temperature - SST," 7th International Symposium on Spatial Accuracy Assessment in Natural Resources and Environmental sciences, Lisboa, 2006, pp. 889-898.

[3] Z. Zhang and K. Friedrich, "Artificial neural network applied to polymer Composites: a review," Computer Science Technology, vol. 63, no. 14, 2003, pp. 2029-2044.

[4] A. Stoic, I. Lackovic, J. Kopac, I. Samardzic, and D. Kozak, "An investigation of machining efficiency of internal roller burnishing," Journal of Achievements in Materials and Manufacturing Engineering, vol. 40, no. 2, 2010, pp.188-194.

[5] N. S. M. El-Tayeb, K. O. Low, and P. V. Brevern, "On the surface and triboligcalcharactrestics of burnshied cylindrical A1-6061," Tribology International, vol. 42, no. 2, 2009, pp. 320-326.

[6] N. S. M. El-Tayeb, K. O. Low and P. V. Brevern, "Influence of roller burnishing contact width and burnishing orientation on surface quality and tribologicalbehaviour of Aluminium 6061," Journal of Materials Processing Technology, vol. 186, no. 1-3, 2007, pp. 272-278.

[7] Z. Zhang and K. Friedrichand K. Velten, "Prediction on tribological properties of short fiber composites using artificial neural networks," Wear, vol. 252, no. 7-8, 2002, pp. 668-675.

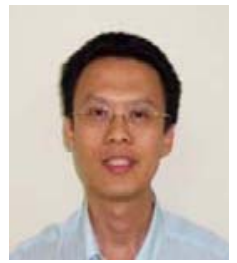

Tang Sai Hong received his PhD and BEng from Dublin City University and Universiti Pertanian Malaysia, respectively. He is an Associate Professor and attaches with the Department of Mechanical \& Manufacturing Engineering, Universiti Putra Malaysia since 1997. Currently, he works in the fields of robotics, operations research and artificial intelligence. 


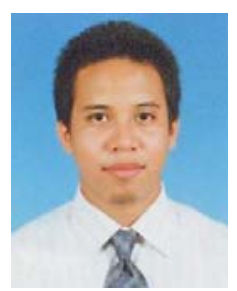

Nasrul Hakim Ab. Rahman received his BEng and Master degrees from Malaysia. He is specialized in artificial intelligence.

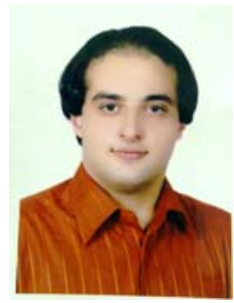

Weria Khaksar received his BE degree of Industrial Engineering from Kurdistan University, Sanandaj, Iran, and Master's degree from Islamic Azad University, Sanandaj, Iran, in 2004 and 2007, respectively. $\mathrm{He}$ is a $\mathrm{PhD}$ candidate in the field of Industrial Engineering in the Universiti Putra Malaysia, Malaysia. He has worked in many robotic research areas under several grants at UPM since 2008. His research areas include path planning, artificial intelligence and optimization.

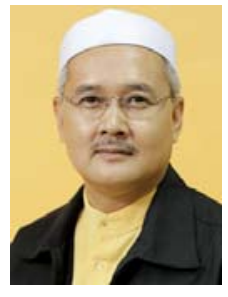

Shamsuddin Sulaiman is a Professor in the Department of Mechanical \& Manufacturing Engineering, Universiti Putra Malaysia. He received his BEng from Malaysia, and obtained his MSc and $\mathrm{PhD}$ from United Kingdom. His research areas are casting technology, manufacturing engineering and $\mathrm{CAD} / \mathrm{CAM}$.

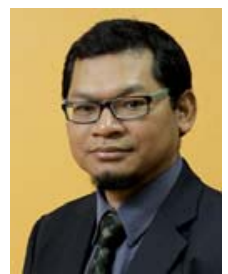

Mohd Khairol Anuar Mohd Ariffin is an Associate Professor in the Department of Mechanical \& Manufacturing Engineering, Universiti Putra Malaysia. He received his BEng and PhD from United Kingdom, and obtained his MSc from Malaysia. His research areas are manufacturing engineering and optimization.

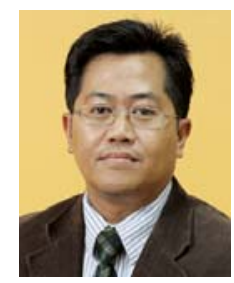

Razali Samin is a Professional Engineer in the Department of Mechanical \& Manufacturing Engineering, Universiti Putra Malaysia. He received his BEng and MSc from Malaysia. His research areas are automation and robotics, dynamics and control. 